\title{
Vibrational and numerical evaluation of human incus mechanical properties
}

\author{
V. Gylienė*, N. Kraptavičiūtė*, P. Lipinski**, S. Wronski***, R. Rahouadj****, \\ J. Tarasiuk***, A. Baldit**, G. Gylys*****, K. Norkaitytė***** \\ *Kaunas University of Technology, Studentu 56, LT-51424 Kaunas, Lithuania, \\ E-mail:virginija.gyliene@ktu.lt,neringa.kraptaviciute@ktu.edu \\ **University of Lorraine, ENIM - LaBPS, 1 route d'Ars Laquenexy, FR-57078 Metz Cedex 3, France, \\ E-mail: pawel.lipinski@univ-lorraine.fr, adrien.baldit@univ-lorraine.fr \\ ***AGH University of Science and Technology, Al Mickiewicza 30, PL-30059 Krakow, Poland, \\ E-mail:wronski.sebastian@gmail.com,tarasiuk@agh.edu.pl \\ ****University of Lorraine, LEMTA, 2 Ave Foret Haye, TSA 60604, F-54518 Vandoeuvre Les Nancy, France, \\ E-mail: rachid.rahouadj@univ-lorraine.fr \\ *****Lithuanian University of Health Sciences, Department of Oto-Rhino-Laryngology, Eiveniu 2, LT-50009 Kaunas, \\ Lithuania,E-mail: gylysg@yahoo.com,nork.kristina@gmail.com
}

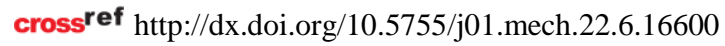

\section{Introduction}

The mechanism of hearing involves conduction of mechanical vibrations along the ossicular chain to the inner ear [1]. The middle ear system with its smallest bones and articulations is responsible for catching noise energy and transforming it to perilymph pressure changes in the cochlea. The ossicular chain (the malleus, the incus and the stapes - Fig. 1) connects the tympanic membrane and the inner ear, and plays an important role in amplifying and regulating sound waves [2]. In doing so the spatial motion of the ossicular chain appears as the one of main causes of the hearing quality [3].

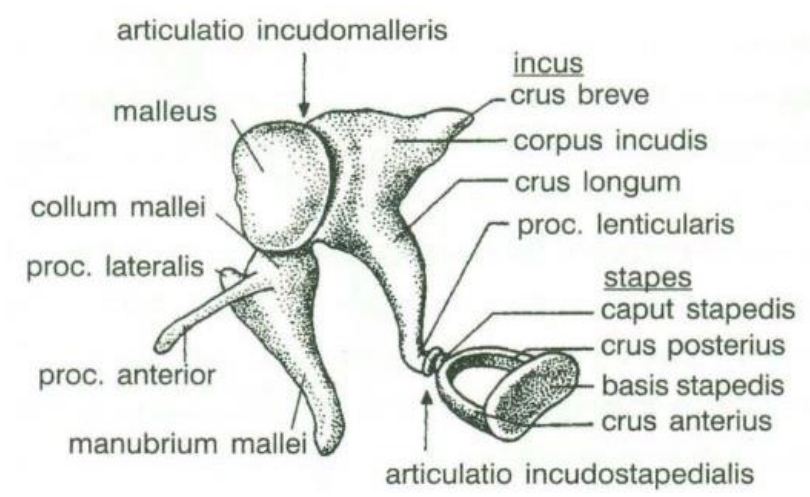

Fig. 1 The ossicular chain of human ear [4]

The degree of ossicular chain deterioration or damage in humans, as a result of inflammatory disease, trauma or malformation, is variable [5]. Of the three ossicles from the middle ear, the incus was often reported in literature to be the most eroded bone and the more distant from the inflammation focus [6, 7]. Borgstein et al [8] highlighted, that the problem of erosion of the incus is a frequently observed, but rarely discussed problem. Park [9] also examined the problems of the long process of incus but caused by congenital origin. Finally, Yuang [10] summarised ossicular damage in the patients with atelectasis and found that for $72 \%$ of cases in posterior retraction pocket only incus was eroded.
There are many ways to reconstruct the ossicular chain, but the results are not always satisfactory because it is being done usually by columella (bird) effect, which sometimes is unsatisfactory for hearing impairment. Sometimes, some artificial materials, as glue [11] for example, could be used to reconstruct the ossicular chain discontinuity. Or the use of glass ionomer cement to repair incus long process defects is a suitable method that improves hearing in pediatric patients [12]. It is hypothesised that the function of the malleus-incus-stapes arrangement is to link the drum to the oval window with the flexibility required for impedance matching but the rigidity to prevent unconstrainable resonances from occurring in the hearing range [1]. If it is true, then the structural stiffness of ossicular chain is the critical design for middle-ear replacement prostheses.

Nevertheless, the substituting materials should fit according to the material characteristics; the geometrical requirements are also important. Kaftan et al [5] accentuate that the most difficult situation is to evaluate the length of prosthesis. For this kind of problems, and others, the finite element method (FEM) has distinct advantages in modelling complex biological systems when compared to other techniques [13]. Even, as reported in [14], it could improve the clinical surgical intervention.

Consecutively to ossicles' surgery, the surgeons are observing that incus bone work does not depend only on degradation level and affected area size. It was also observed that sometimes damaged bone part is large but it does not affect bone work in whole hearing system and opposite - the bone degradation level can be low but the ossicles not functioning well. From these observations one could make a hypothesis that the bone work is mainly affected by the bone microstructure and mechanical properties. Also, it can suppose that location of the focus of infection affects bone strength and its ability to transmit vibrations.

To confirm or deny this hypothesis a study of the middle ear bone incus microstructure and mechanical properties was undertaken.

To identify bone microstructure $\mu$ CTomograph was used to evaluate bone porosity and to identify bone quality. In order to find actual value of incus bone Young's 
modulus, the modal analysis using piezoelectric system was performed. Accordingly, it was decided to extract the average bone properties by inverse method based on the eigenvalue measurements and calculations. Consequently, FE model was composed for selected incus sample.

\section{Incus testing procedures}

In total, four incus bones were prepared for this study. Each incus bone was removed due to surgical treatment. Also, each sample was coded for the privacy of patients. After using microscope with magnification of 20 all samples were visually inspected to identify their condition. It was found that the less damaged was the sample coded as ' $1 \mathrm{M}$ ' (sex of patient: women) (Fig. 2).

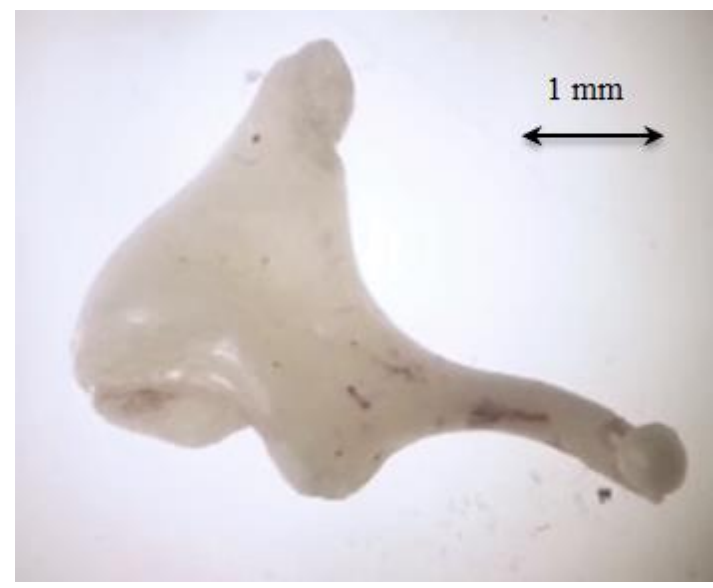

Fig. 2 Aspect of $1 \mathrm{M}$ incus sample through a microscope

After visual inspection with optical microscope, all samples were left to dry at room temperature and controlled humidity. The high precision balance Sartorius CPA225D was used to perform the mass evaluations. The mass of sample $1 \mathrm{M}$ was measured immediately after removal from the refrigerator and from formaldehyde solution. The results indicate that the mass variation for sample $1 \mathrm{M}$ was about $0.2 \%$. From the line-chart (Fig. 3) we can see that the sample mass has no clear tendency to increase or to decrease during 98 hours period.

It could be said, that the mass changes are mainly due to the ambient moisture variations. It can be concluded, that keeping samples in the formaldehyde liquid does not affect their mass. It could mean that incus bones are compact tissues.

Before tomography test each sample was glued to the plastic rod, which served as a support during scanning. The X-ray measurements were performed using "nanotom180N" device produced by GE Sensing \& Inspection Technologies phoenix|X-ray Gmbh. During the measurement the tungsten target was used. The working parameters of X-ray tube were $V=60 \mathrm{kV}$ and $I=310 \mu \mathrm{A} .1500$ projections were taken with an exposure time of 500 miliseconds with 4 integrations for each exposition. The total time of measurement was around $60 \mathrm{~min}$. The reconstruction of measured objects was done with the aid of proprietary GE software datosX ver. 2.1.0 with use of Feldkamp algorithm for cone beam X-ray CT [15]. The final resolution of reconstructed object was $3.5 \mu \mathrm{m}$.

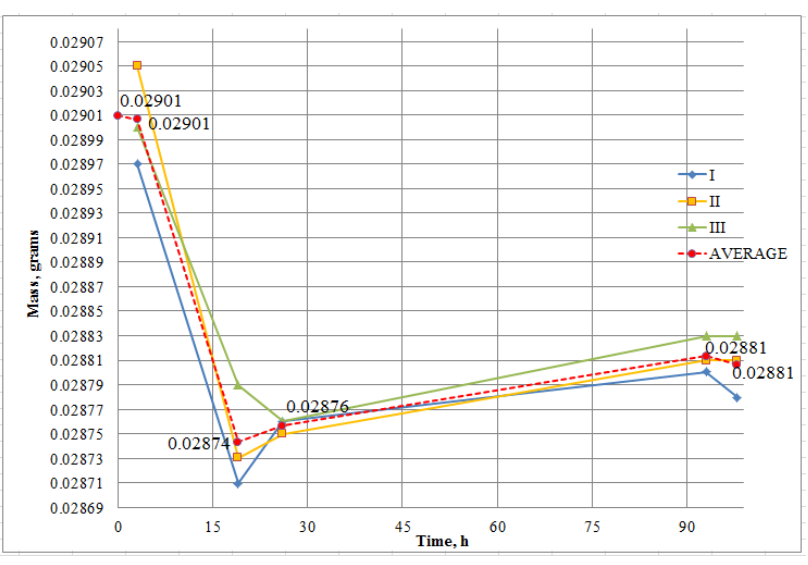

Fig. 3 The results of mass measurements

The tomography analysis results showed that porosity in incus bone is variable in its different sites testifying the highly heterogeneous character of the bone mechanical properties (Fig. 4).

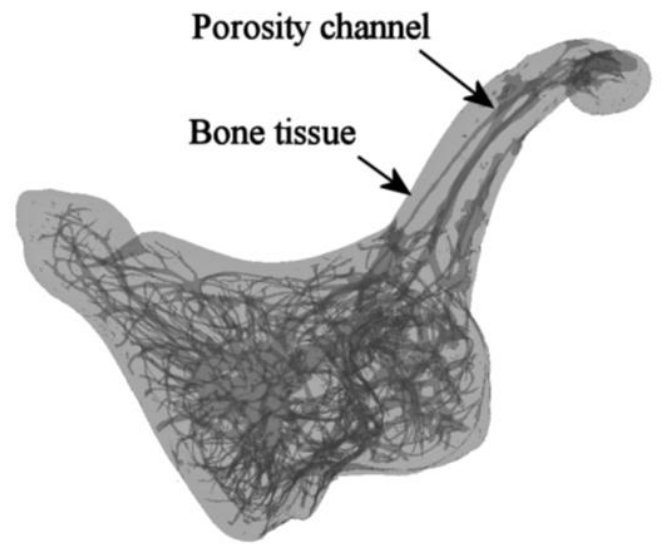

Fig. 4 The porosity of incus sample $1 \mathrm{M}$

After scanning, the volume of each sample was next calculated using image processing software $\mathrm{Fiji}^{\circledR}$. Firstly, from all scanned slides we eliminated slides including aluminium particle and support. Binariesed data was then prepared consisting only of white and black pixels. Finally, threshold values were set enabling the calculation of volumes of sample. The volume of sample $1 \mathrm{M}$ was calculated twice: firstly, as for the others samples, using scan results and later for the same model but with manually eliminated porosity. This was done in order to compare volumes and validate the FE model.

Table 1 presents the results from $\mu$ CTomography. It can be summarized, that thanks to the tomography analysis results, the complex microstructure of the sample was found and its volume and density was precisely calculated with and without the sample porosity.

Table 1

Incus properties, obtained from $\mu \mathrm{CT}$ Tomography

\begin{tabular}{|c|c|c|c|}
\hline $\begin{array}{c}\text { Sample } \\
1 \mathrm{M}\end{array}$ & $\begin{array}{c}\text { Bone volume, } \\
\mathrm{mm}^{3}\end{array}$ & $\begin{array}{c}\text { Mass, } \\
\mathrm{g}\end{array}$ & $\begin{array}{c}\text { Density, } \\
\mathrm{g} / \mathrm{mm}^{3}\end{array}$ \\
\hline without pores & 14.163 & 0.02881 & 0.002034 \\
\hline with pores & 13.240 & 0.02881 & 0.002176 \\
\hline
\end{tabular}


Various experimental methods can be used to identify the mechanical properties of materials or tissues. The classical mechanical tests such as traction, compression or torsion are frequently used to characterize the properties of materials such as metals or polymers. However, they require the sufficient amount of matter to machine the standard samples. Moreover, they belong to the so-called destructive tests. Recently, nano-indentation has been recognized as a powerful method to estimate local values of Young's modulus of the materials $[16,17]$.

As the classical tests mentioned above, this method leads to a local deterioration of the tested material. Also, it only provides the local information concerning the elastic properties of the material tested which can strongly change from site to site of the substantially porous and inhomogeneous incus bone. On the other hand, ultrasonic methods based on the measurement of sound wave celerity provide convenient way to characterize the elastic properties of materials and tissues in non-destructive manner. However, the small size of the ossicle proscribes the use of the conventional ultrasonic devices. Consequently, it was decided to extract the average bone properties by inverse method based on the eigenvalues measurement and calculation. Accordingly, the FE model of the incus $1 \mathrm{M}$ was built for Young Modulus identification.

\section{Modal analysis}

To find real value of the average incus bone Young's Modulus we decided to perform a modal analysis using piezoelectric exciter. The experimental test bed was equipped with OPTIKA ${ }^{\circledR}$ TC B5 camera, with resolution of 5Mpixels, and TOE7404 function generator, with frequency range from $50 \mathrm{~Hz}$ to $5 \mathrm{MHz}$. All equipment used for this experimentation is presented in Fig. 5 .

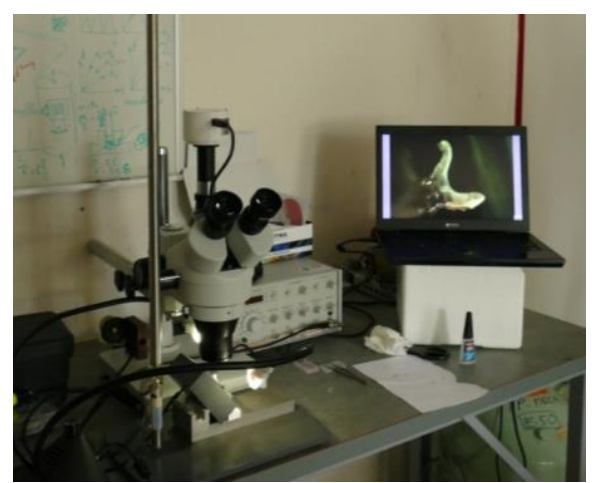

Fig. 5 The set-up for incus vibrational analysis

Two samples (1VS and 1M) were simultaneously glued in the central part of the piezoelectric plate (Fig. 6). One of them was the case study sample - 1M. Malleus-joint surface was chosen as a fixation point. After gluing, samples were left to dry the glue for a few minutes. Next, using function generator, the vibration frequency value was increased slowly from 0 to $30000 \mathrm{~Hz}$.

To see better the body motion and to easily identify frequency range for each mode, camera was zoomed only to the end of the most flexible incus part, i.e. its long process (Fig. 7).

The registered frequency values are summarised in Table 2. As it could be seen from Table 2, only three eigenvalues were obtained for each sample. Two reasons can be mentioned to justify this low number. Firstly, the used piezoelectric plate was not powerful enough to sweep higher frequencies. Secondly, the inspected and found eigenfrequency values concern only the incus long process.

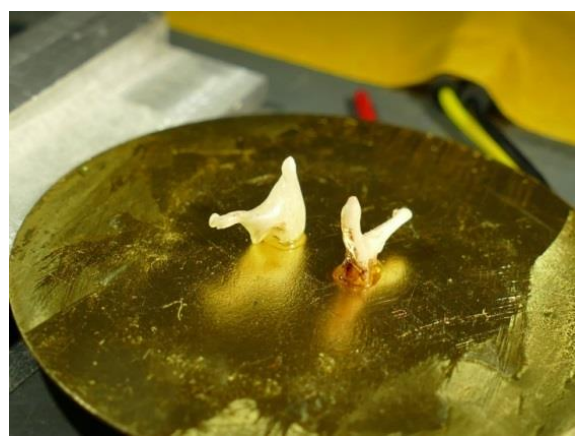

Fig. 6 Samples glued on piezoelectric plate

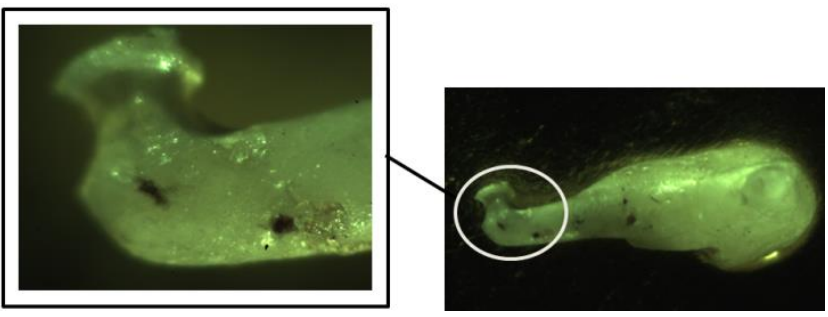

Fig. 7 Zoomed long process part of 1M sample

Table 2

Registered eigenfrequency values

\begin{tabular}{|c|c|c|}
\hline Mode Number & 1VS Sample & 1M Sample \\
\hline 1 & $18.93 \mathrm{kHz}$ & $14.18 \mathrm{kHz}$ \\
2 & $19.96 \mathrm{kHz}$ & $20.67 \mathrm{kHz}$ \\
3 & $38.81 \mathrm{kHz}$ & $30.00 \mathrm{kHz}$ \\
\hline
\end{tabular}

*Remark: sample was not submerged in formaldehyde

\section{Identification of Young Modulus by FE modelling}

After the $\mu \mathrm{CT}$ Tomography scanning the $3 \mathrm{D}$ geometry of incus was "repaired" and meshed. Altair HyperMesh ${ }^{\circledR}$ Software was used to close all surface holes and to make the 3D numerical model smooth. To verify the convergence of the results two types of tetrahedral elements (linear and quadratic) were used. Finally, the quadratic (10 nodes) element type was selected for numerical simulation (Fig. 8).

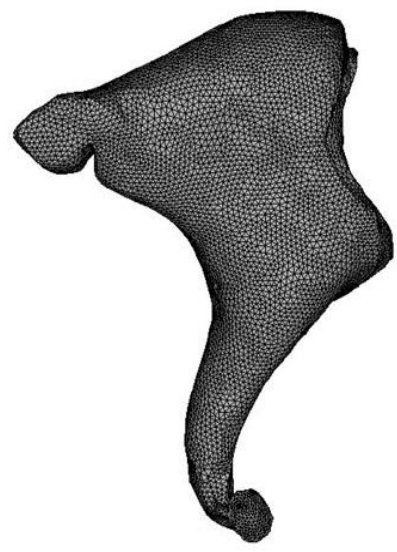

Fig. 8 Meshed incus model with quadratic (10 nodes) element type 
After the meshing, 3D model was exported to MSC Marc ${ }^{\circledR}$ Software. The initial material mechanical properties were chosen with reference to literature [18]. We have chosen the value of $1.41 \times 10^{10} \mathrm{~Pa}$ for its Young's Modulus and 0.28 as the Poisson's ratio. As it was found in the literature $[13,19]$ but also as a results of our tomography analysis, the porosity or internal architecture of bone is not homogeneous and differs from part to part of the bone.

Consequently, the density of the incus is not the same in the different parts also. It means that the bone has different mechanical properties in every part. For this reason, as it can be seen in Fig. 9 the FE model was divided in three parts - body (in pink), short process ( $\mathrm{SP}$ - in yellow) and long process ( $\mathrm{LP}-$ in red).

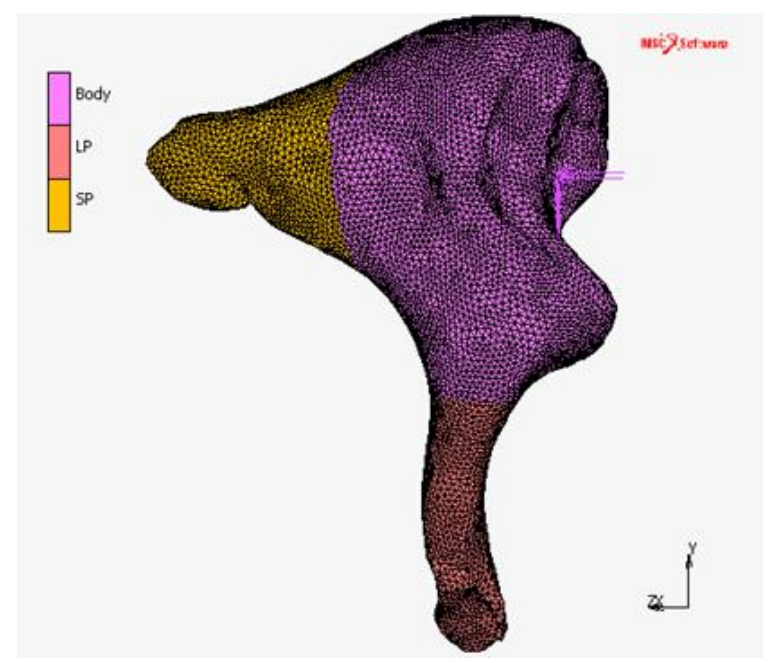

Fig. 9 3D meshed model divided in three sections: body, long process (LP) and short process (SP)

Concerning the boundary conditions, three neighbouring nodes on malleus-joint surface were constrained in $\mathrm{X}, \mathrm{Y}, \mathrm{Z}$ directions as materialized by arrows in Fig. 9. As a first verification, the volume of FE model was calculated using the MSC Marc ${ }^{\circledR}$ Software. The result showed that volume of $1 \mathrm{M}$-sample model was equal to $14.220 \mathrm{~mm}^{3}$. If we compare this value with the results from $\mu \mathrm{CT}$ Tomography analysis for the same sample $1 \mathrm{M}$ taking into account the specimen porosity $\left(V=13.240 \mathrm{~mm}^{3}\right)$, it clearly appears that the finite element mesh volume is bigger than that calculated with Fiji ${ }^{\circledR}$ software.

However, if we compare the same mesh associated volume with $1 \mathrm{M}$ sample considered as a continuum body $\left(V=14.163 \mathrm{~mm}^{3}\right)$ it appears that the difference is only $0.132 \mathrm{~mm}^{3}$, i.e. less than $0.9 \%$. Because the volume difference between FE model and 1M-sample without pores is very small, it could be concluded, that our 3D FE model is sufficiently precise for numerical analysis.

To identify elastic properties of our sample we decided to deduce the Young's modulus value by fitting results from vibration test. 3D FE model of 1M-sample with quadratic element type 184 of Marc library (Full Integration \& Assumed Strain) was used in order to extract the eigenfrequencies of the sample. 10 calculations were done by changing Young Modulus to fit the experimentally determined eigenfrequencies. The calculations started with the value of Young Modulus equal to $1.41 \times 10^{10} \mathrm{~Pa}$ [18].

The resulting eigenfrequencies showed that the
Young's Modulus equal to $4.5 \times 10^{+09} \mathrm{~Pa}$ provided the response closest to the experimentally obtained eigenvalues. Also, it should be mentioned that these calculations were made using bone model in which porosity was not included. Secondly, the inhomogeneity in the FE model was introduced. According to the literature $[13,19,20]$ the eigenvalue calculations were performed with different value of long process density equal to $5080 \mathrm{~kg} / \mathrm{m}^{3}$ comparing to body density of $2030 \mathrm{~kg} / \mathrm{m}^{3}$. By doing this, it was found that when the density of our sample is not homogeneous the frequency values obtained for $E=4.5 \times 10^{+09} \mathrm{~Pa}$ are lower than experimental ones. Consequently, the Young's Modulus was increased to $E=6 \times 10^{+09} \mathrm{~Pa}$, enabling us to fit better the experimental values.

\section{Conclusions and discussions}

In order to identify incus bone microstructure and mechanical properties, firstly the mass of the sample was measured. It was noticed that mass changes appeared because of the ambient humidity variation, but not because of bone water contents. Bone volume and microstructure analysis was performed using $\mu$ CTomograph. From tomography results we founded that microstructure and porosity of bone are not homogeneous and differ from part to part of the bone. It could be said, that our samples are more porous than typical cortical bone.

To find actual value of incus bone Young's Modulus, the experimental modal analysis was made. Due to piezoelectric plate power problems and results registration method based on the visual inspection of sample motion in one direction, only three frequency values were identified. Comparing frequency values obtained from experiment with frequencies calculated by changing Young's Modulus value, it was found that the calculated eigenfrequencies are closest to real values if the Young's Modulus of the incus is equal to $4.5 \times 10^{+09} \mathrm{~Pa}$. However the obtained results are only indicative, because calculations were made not taking into account the bone porosity.

Moreover, on purpose to find out incus bone mechanical properties, the real density of each bone part has to be identified. Also, to get reliable results, all calculations should be repeated using bone model with porosity. Furthermore, it is important to mention that, to get reliable results for this research more than one computational model should be used.

\section{Acknowledgements}

The preparation of samples was performed fulfilling the requirements of ethical committee of Lithuanian University of Health Sciences.

\section{References}

1. Ferris, P.; Prendergast, P.J. 2000. Middle-ear dynamics before and after ossicular replacement, J. Biomech. 33(5): 581-590. http://dx.doi.org/10.1016/S0021-9290 (99)00213-4.

2. Stoessel, A.; Gunz, P.; David, R.; Spoor, F. 2016. Comparative anatomy of the middle ear ossicles of extant hominids - Introducing a geometric morphometric protocol, J. Hum. Evol. 95: 1-25. 
http://dx.doi.org/10.1016/j.jhevol.2015.10.013.

3. Kovincic, N.I.; Spasic, D.T. 2016. Dynamics of a middle ear with fractional type of dissipation, Nonlinear Dyn. 85(4): 2369-2388. http://dx.doi.org/10.1007/s11071-016-2832-z.

4. Stropus, R.; Tamašauskas, K.A.; Paužienė, N. 2005. The human anatomy [online, accessed 6 June 2016], Available from Internet: http://ebooks.vitaelitera.lt/eb/ 1449/zmogaus-anatomija/ (in Lithuanian).

5. Kaftan, H.; Böhme, A.; Martin, H. 2015. Parameters for novel incus replacement prostheses, Eur. Arch. Otorhinolaryngol. 273(9): 2411-2417. http://dx.doi.org/10.1016/10.1007/s00405-015-3810-7.

6. Albera, R.; Canale, A.; Piumetto, E.; Lacilla, M.; Dagna, F. 2012. Ossicular chain lesions in cholesteatoma, Acta Otorhinolaryngol. Ital. 32(5): 309-313.

7. Duboeuf, F.; Burt-Pichat, B.; Farlay, D.; Suy, P.; Truy, E.; Boivin, G. 2015. Bone quality and biomechanical function: A lesson from human ossicles, Bone. 73: $105-110$. http://dx.doi.org/10.1016/j.bone.2014.12.009.

8. Borgstein, J.; Gerritsma, T.V.; Bruce, I.A. 2008. Erosion of the incus in pediatric posterior tympanic membrane retraction pockets without cholesteatoma, Int. J. Pediatr. Otorhinolaryngol. 72(9): 1419-1423. http://dx.doi.org/10.1016/j.ijport.2008.06.004.

9. Park, K.; Choung, Y.-H.; Shin, Y. R.; Hong, S.P. 2007. Conductive deafness with normal eardrum: absence of the long process of the incus, Acta Otolaryngol. 127(8): 816-820. http://dx.doi.org/10.1080/00016480601075449.

10. Yung, M.W. 1997. Retraction of the pars tensa longterm results of surgical treatment, Clin. Otolaryngol. Allied Sci. 22(4): 323-326. http://dx.doi.org/10.1046/j.1365-2273.1997.00018.x.

11. Gungor, V.: Atay, G.; Bajin, M. D.; Yarali, M. Sarac, S.; Sennaroglu, L. 2016. Comparison of various bone cement ossiculoplasty techniques and functional results, Acta Oto-Laryngol. 136 (9): 883-887. http://dx.doi.org/10.3109/00016489.2016.1172255.

12. Atan, D.; Dere, H.; Yamur, A.R.; Ozcan, K.M. 2016. Results of ossicular chain reconstruction with glass ionomer cement in pediatric patients, Int. J. Pediatr. Otorhinolaryngol. 85: 103-106. http://dx.doi.org/10.1016/j.ijporl.2016.03.027.

13.Sun, Q.; Gan, R.Z.; Chang, K.-H.; Dormer, K.J. 2002. Computer-integrated finite element modeling of human middle ear, Biomech. Model. Mechanobiol. 1(2): $109-122$ http://dx.doi.org/10.1007/s10237-002-0014-z.

14. Volandri, G.; Di Puccio, F.; Forte, P.; Carmignani, C. 2011. Biomechanics of the tympanic membrane, J Biomech. 44(7): 1219-1236. http://dx.doi.org/10.1016/j.jbiomech.2010.12.023.

15. Feldkamp, L.A.; Davis, L.C.; Kress, J.W. 1984. Practical cone-beam algorithm, JOSA A, 1(6): 612-619.
16. Panich, N.; Yong, S. 2005. Improved method to determine the hardness and elastic modulus using nanoindentation, KMITL Sci. Tech. J. 5(2): 483-492.

17. Oliver, W.C.; Pharr, G.M. 1992. An improved technique for determining hardness and elastic modulus using load and displacement sensing indentation experiments, J. Mater. Res. 7: 1564-1583.

18. Zhang, X.; Guan, X.; Nakmali, D.; Palan, V.; Pineda, M.; Gan, R.Z. 2014. Experimental and modeling study of human tympanic membrane motion in the presence of middle ear liquid, Jaro-J. Assoc. Res. Otolaryngol. 15(6): 867-881. http://dx.doi.org/10.1007/s10439-012-0624-2.

19. Liu, H.; Rao, Z.; Huang, X.; Cheng, G.; Tian, J.; Ta, N. 2014. An incus-body driving type piezoelectric middle ear implant design and evaluation in 3D computational model and temporal bone, Sci. World J. 121624:18. http://dx.doi.org/10.1155/2014/121624.

20. Lee, D.; Ahn, T.-S. 2015. Statistical calibration of a finite element model for human middle ear, J. Mech. Sci. Technol. 29 (7): 2803-2815. http://dx.doi.org/ 10.1007/s12206-015-0609-9.

V. Gylienė, N. Kraptavičiūtė, P. Lipinski, S.Wronski, R. Rahouadj, J. Tarasiuk, A. Baldit, G. Gylys, K. Norkaitytè

\section{VIBRATIONAL AND NUMERICAL EVALUATION OF HUMAN INCUS MECHANICAL PROPERTIES}

S u m m a r y

The capabilities to apply the FEM in hearing research field are large: the identification of tissues properties, the definition of the behaviour of hearing elements or even it could improve the clinical surgical intervention. Numerous researchers are focused on hearing improvement or understanding problems by working on middle ear or inner ear behaviour.

In our work we focused on mechanical properties identification of incus by using micro-CT scanning, performing vibrational analysis and finally the FE simulations. Contrarily to other researchers we supposed incus bone to be non-homogeneous body and accordingly attributed different densities in long and short processes. The non-homogeneity of the long and short processes could be the reason why the incus bone behaviour does not depend simply on degradation level and affected area size. Finally, by inverse FE modelling, the Young Modulus was estimated.

Keywords: Finite element modelling, mechanical properties, hearing, incus.

Received October 27, 2016 Accepted December 2, 2016 